\title{
INSERÇÃO DE ENFERMEIRAS OBSTETRICAS NO ATENDIMENTO AO PARTO: PERCEPÇÃO DA EQUIPE DE ENFERMAGEM
}

\author{
INSERTION OF OBSTETRIC NURSES IN THE CARE OF THE BIRTH: PERCEPTION OF
}

\author{
THE NURSING TEAM
}

\author{
Renata Martins da Silva ${ }^{1}$ \\ Karen Chaves Linhares ${ }^{2}$ \\ Samara da Silva Guimarães ${ }^{3}$ \\ Maria da Glória Malta ${ }^{4}$ \\ Ilda Cecília Moreira da Silva ${ }^{5}$ \\ Recebido em: 19 jul. 2017 \\ Aceito em: 16 jun. 2018
}

RESUMO: O objetivo do estudo foi conhecer a opinião da equipe de enfermagem de um hospital público sobre a inserção de enfermeiras obstétricas na atenção ao parto normal. Estudo de campo, qualitativo, onde participaram dez profissionais de enfermagem, que atuam na maternidade de um hospital do município de Volta Redonda (RJ). A análise de dados foi construída a partir do material proveniente dos questionários e permitiu uma apreensão de significados positivos atribuídos pelas participantes à inserção de enfermeiras obstétricas na sala de parto. Como resultados surgiram as seguintes categorias: Acolhimento como forma de humanização do parto; Papel da Enfermeira na Ambientação para o Parto Humanizado e Enfermeira obstétrica como referência no parto. A equipe espera que com a inserção da enfermeira obstétrica atuando na assistência, proporcione experiências de educação em saúde para equipe de enfermagem e também para as parturientes para que estas estejam conscientes de seus direitos. Conclui-se que a equipe espera que a enfermeira seja uma referência para humanização do atendimento ao parto.

Palavras-chave: Parto humanizado. Enfermeira obstetra. Saúde da mulher.

ABSTRACT: The objective of the study was to know the opinion of the nursing team of a public hospital about the insertion of obstetrical nurses in the attention to normal delivery. Field study, qualitative, where ten nursing professionals participated, who work in the maternity of a hospital in the city of Volta Redonda (RJ). The data analysis was constructed from the questionnaires' material and allowed the apprehension of positive meanings attributed by the participants to the insertion of obstetric nurses in the delivery room. As results the following categories emerged: Welcoming as a form of humanization of childbirth; Role of the Nurse in the Setting for Humanized Delivery and Obstetric Nurse as reference in childbirth. The team hopes that with the insertion of the obstetric nurse acting in the assistance, provide experiences of health education for nursing staff and also for the parturients so that they are aware of their rights. It is

\footnotetext{
${ }^{1}$ Doutoranda do Programa de Pós-graduação em Enfermagem e Biociências (UNIRIO) Docente do Curso de Enfermagem do UniFOA.

2 Acadêmica de Enfermagem do UniFOA.

${ }^{3}$ Acadêmica de Enfermagem do UniFOA.

${ }^{4}$ Docente do curso de Enfermagem do UniFOA. Especialista em Docência do Ensino Superior.

${ }^{5}$ Doutora em Enfermagem. Docente do Curso de Enfermagem do UniFOA.
} 
concluded that the team expects the nurse to be a reference for the humanization of childbirth care.

Keywords: Humanized birth. Midwife. Women's health.

\section{INTRODUÇÃO}

O modelo de parto normal se modificou através do tempo, passando de um parto domiciliar atendido por mulheres para um parto hospitalar e medicalizado. Entretanto na atualidade, políticas públicas surgem para dar conta de um novo desafio, o resgate de uma atenção ao parto mais humanizada e que atenda as expectativas da parturiente independente do local onde ocorre o parto - domicílio, Centro de Parto Normal extra, peri ou intra hospitalar e maternidade.

O nascimento é historicamente um evento natural, como também é indiscutivelmente um fenômeno mobilizador, mesmo as primeiras civilizações agregaram a este acontecimento inúmeros significados culturais, que através de gerações sofreram transformações. (MOURA, 2004). Essas transformações refletem expressões de âmbito cultural, familiar e social de um povo em determinada época que interferem nos modelos de parto e de assistência a saúde.

"O parto humanizado é entendido como prática de cuidado ao parto e ao nascimento, garantindo uma qualidade de assistência segura que valoriza a escolha do ato de dar à luz de forma natural privativa e familiar." O parto visto como natural e próprio do ciclo de vida da mulher, atendido de forma a respeitar a vontade da parturiente e da família, de forma segura e em harmonia com as necessidades dos mesmos. (PEREIRA, 2016)

Desta forma, considerando o contexto histórico e a ampliação de Políticas Públicas, de promoção à saúde integral e humanizada, mudanças estruturais e gerenciais tornam-se necessárias para atender às demandas de atenção ao parto. Dentre elas a consolidação do papel da enfermeira obstétrica como agente de mudanças no cotidiano do parto.

O Ministério da Saúde tem instituído diretrizes para o apoio ao parto normal fisiológico através da Rede Cegonha que no Art. $1^{\circ}$ da lei que a institui, a define como uma rede de cuidados que visa assegurar à mulher o direito ao planejamento reprodutivo e à atenção humanizada à gravidez, ao parto e ao puerpério, bem como à criança o direito ao nascimento seguro e ao crescimento e ao desenvolvimento saudáveis. (MINISTERIO DA SAUDE, 2011)

O Ministério da Saúde com a implantação da Rede Cegonha a partir de 2011 preconiza a humanização durante o atendimento ao parto normal, a livre escolha da mulher de seu acompanhante, o acompanhamento do pré-natal de forma qualificada e ainda a ampliação das equipes de atenção ao parto normal de forma horizontal, e com isso a inserção de enfermeiras obstetras para o acompanhamento do parto.

Nesta Linha de Cuidado criada pelo Ministério da Saúde é prevista a criação de estruturas de assistência como as Casas de Parto Normal, casa do bebê e a casa da 
gestante, locais estes onde o enfermeiro obstetra tem uma importante atuação e realiza práticas que visam humanizar cada procedimento realizado durante o parto.

$\mathrm{Na}$ LEI 7.498, de 25 de Junho de 1986 ao enfermeiro é garantida a autonomia na assistência à parturiente e ao parto normal com a Especialização em Enfermagem Obstétrica; Identificação das distócias obstétricas e tomada de providências até a chegada do médico; realização de episiotomia e episiorrafia e aplicação de anestesia local, quando necessária. (COFEN, 1986)

A enfermeira obstetra tem uma formação não medicalizada e que busca os fundamentos de sua prática no parto humanizado com menos intervenções e utiliza métodos não farmacológicos de alívio da dor no parto. Frello e Carraro (2010) reforçam que no parto humanizado deve-se dar liberdade às escolhas da parturiente, prestando um atendimento focado nas necessidades apresentadas a cada momento.

A formação em obstetrícia confere à enfermeira habilidades e competências que a possibilitam ter uma visão integral da situação, cuidando do que é fundamental, ou seja, desde a temperatura da sala, até a luminosidade e o silêncio, para que cada mulher sintase livre e à vontade para mudar de posição, andar, sanar suas dúvidas e ser atendida de forma que sua autonomia seja respeitada. (CAUS, 2012)

$\mathrm{Na}$ relação empática, o profissional tem a percepção das necessidades da parturiente que, muitas vezes, é subjetiva; pelo olhar, pela pele, pelo não dito, pelo silêncio, pelo gesto. É nessa atitude/cuidado que a Enfermeiro Obstétrico responde ao chamado da mulher, esclarecendo suas dúvidas, reanimando sua energia, renovando sua confiança para seguir adiante, permitindo assim que o parto normal se concretize num ambiente agradável. Essa forma de atendimento ao parto pode ser efetiva na maternidade ou no domicílio. (CAUS et al, 2012)

As mudanças de contexto na atenção ao parto vêm sendo discutidas a fim de garantir as mulheres o direito de parir em condições seguras e promover experiências saudáveis e humanizadas ao nascimento.

Em cidades do interior que tem um número reduzido de enfermeiras obstétricas em campo existe a dificuldade em ocupar esse espaço na atenção ao parto que leve à humanização das práticas no parto normal. A Rede Cegonha pode contribuir para um olhar mais esperançoso para profissionais que apóiam essas práticas. Diante disso, este artigo tem como objetivo conhecer a opinião da equipe de enfermagem de um hospital público sobre a inserção de enfermeiras obstétricas na atenção ao parto normal.

\section{MATERIAL E MÉTODOS}

Trata-se de um estudo exploratório com abordagem qualitativa. A abordagem qualitativa, conforme Gerhardt e Silveira (2009) busca explicar o porquê das coisas, sem quantificar os valores e nem submetê-los à prova de fatos, pois os dados analisados não 
são métricos e tratam-se de respostas aos questionários aplicados.

O cenário escolhido para realização da pesquisa foi a maternidade um hospital público localizado no município de Volta Redonda (RJ). O motivo de escolha deste cenário foi a atual condição de mudanças na maternidade, tanto de estrutura física quanto de modelo assistencial, com a possibilidade de inserção de enfermeiras obstétricas na sala de parto.

O instrumento de coleta de dados utilizado foi o questionário elaborado pelas próprias autoras e que "entende-se por um conjunto de questões que são respondidas por escrito pelo pesquisado". (GIL, 2008, p. 114) As perguntas do questionário foram direcionadas para a experiência da equipe com o parto humanizado e a opinião desta sobre a inserção da enfermeira obstétrica na sala de parto.

As autoras compareceram ao Centro Obstétrico e a maternidade e abordaram de forma aleatória membros da equipe de enfermagem no horário de seus plantões. Os critérios de inclusão foram tempo de experiência de um ano ou mais no setor de maternidade e aceitar participar do estudo assinando o Termo de Consentimento Livre e Esclarecido. Desta forma responderam ao questionário dez profissionais de enfermagem lotadas nos setores de maternidade e Centro Obstétrico.

O presente estudo obedeceu às normas e diretrizes da Resolução 466/2012 do Conselho Nacional de Saúde - CNS, que regulamenta os aspectos legais para Pesquisas com Seres Humanos e foi aprovado pelo Comitê de Ética sob número do Parecer: 1.532.237.

\section{RESULTADOS E DISCUSSÃO}

A análise de dados foi construída a partir do material proveniente dos questionários e permitiu uma apreensão de significados positivos atribuídos pelas participantes à inserção de enfermeiras obstétricas na sala de parto onde as mesmas atuam. As idéias deram origem às seguintes categorias: Acolhimento como forma de humanização do parto; Papel da Enfermeira na Ambientação para o Parto Humanizado e Enfermeira obstétrica como referência no parto.

\section{CATEGORIA 1: ACOLHIMENTO COMO FORMA DE HUMANIZAÇÃO DO PARTO}

As profissionais de enfermagem que participaram do estudo demonstraram empatia com as parturientes e referiram que $o$ acolhimento da equipe pode influenciar positivamente no parto tornando-o mais humanizado, o que pode ser reforçado com a presença e atuação da enfermeira obstétrica na sala de parto.

A questão do acolhimento deve ser discutida quando se propõe um novo modelo de assistência que vise a humanização das práticas na atenção a saúde. As falas das 
participantes refletem mudanças recentes na organização de suas práticas, onde a presença do acompanhante e a possibilidade de oferecer maior liberdade à parturiente pode consolidar e reforçar o acolhimento, permitindo que novos profissionais experimentem essa realidade e reproduzam tais práticas de forma humanizada.

De acordo com o Ministério da Saúde (2016), mulheres em trabalho de parto devem ser tratadas com respeito, ter acesso às informações baseadas em evidências e serem incluídas na tomada de decisões. Para isso, os profissionais que as atendam deverão estabelecer uma relação de intimidade com estas, perguntando-Ihes sobre seus desejos e expectativas. Os profissionais devem estar conscientes da importância de sua atitude, do tom de voz e das próprias palavras usadas, bem como a forma como os cuidados são prestados.

As falas abaixo refletem a concepção das participantes quanto ao acolhimento dispensado às parturientes e sua relação com a humanização das práticas e aproximação com o recomendado pelo Ministério da Saúde:

\footnotetext{
Um parto onde a paciente possa se sentir acolhida. (Dep. 1)

É um parto aonde a gestante tem uma equipe dando um melhor acolhimento; ficando junto ao paciente. (Dep. 6)

Acolhimento da paciente, dela se sentir bem no momento de felicidade, ela estar com quem ela se sente bem, ter alguém do lado para acalmar. (Dep. 9)
}

A maternidade pesquisada tem passado por modificações estruturais e organizacionais para facilitar o atendimento às normas e recomendações do Ministério da Saúde para atendimento ao parto e puerpério preconizadas pela Rede Cegonha, dentre elas a presença do acompanhante. A Lei $n^{\circ} 11.108$, de 07 de abril de 2005, que garante as parturientes o direito à presença de acompanhante durante o trabalho de parto, parto e pósparto imediato no âmbito do SUS; este fato torna-se relevante, pois traz conforto e segurança a mulher, além de auxiliar na disseminação de informações e educação a saúde da família como um todo.

"Para garantir a segurança e o bem-estar da mulher durante o momento do parto normal é indispensável uma atenção adequada e de qualidade, por isso, a equipe de saúde deve estar pronta para acolher a gestante e seus familiares/acompanhantes." (PEREIRA, 2016) A inserção da enfermeira obstétrica na sala de parto está entre os próximos passos a fim de favorecer o acolhimento das parturientes e acompanhantes.

Percebeu-se que a equipe de enfermagem entende a importância do acolhimento como forma de humanização. Que este deve ser ofertado pela equipe, pois isso contribui para o bem estar emocional da parturiente e para uma experiência de parto positiva e de felicidade que pode ser divulgada e reproduzida em novos nascimentos.

\section{CATEGORIA 2: PAPEL DA ENFERMEIRA NA AMBIENTAÇÃO PARA O PARTO}


HUMANIZADO

As profissionais entendem a necessidade de mudanças estruturais para atender às necessidades das parturientes na hora do parto. Indiscutivelmente a presença de profissionais qualificados e com formação voltada para a humanização das práticas, como é o caso da enfermeira obstétrica, afetaria de forma muito positiva o cuidado durante o parto e a ambientação para o parto humanizado.

Como exemplo, o uso de bolas para exercícios, massagens, cadeiras e bancos para posição de cócoras, banhos de imersão, entre outros são métodos facilitadores e que permitem um controle não farmacológico da dor no trabalho de parto e que seriam utilizados pela enfermeira obstétrica com propriedade e de forma a valorizar tais tecnologias de cuidado.

Os gestores nacionais e locais devem proporcionar condições para o redesenho das unidades de assistência ao parto visando a oferta da imersão em água para as mulheres no trabalho de parto. (MINISTÉRIO DA SAÚDE, 2016) Esses métodos quando utilizados adequadamente tornam o processo menos medicalizado e mais humanizado.

A equipe alegou não possuir todos os acessórios para incentivar e atender ao parto de forma humanizada, mas procuram dentro do possível fazê-lo da melhor forma proporcionando conforto e estando ao lado das parturientes mesmo com poucos recursos.

E ainda percebe-se que a equipe de enfermagem tem o desejo de proporcionar um parto mais acolhedor e põe em prática conhecimentos adquiridos que vão ao encontro das práticas humanizadas de atenção ao parto, como destaca-se nas transcrições abaixo:

\footnotetext{
Não temos todos os acessórios disponíveis, mas procuramos dentro do possível colocar nosso aprendizado em prática. (Dep. 4)

Encaminhar a paciente ao chuveiro orientando para deixar a água norma cair sobre a bacia, realizar o exercício com as bolas, deixar o pai acompanhar. (Dep. 6)

O parto é Humanizado quando dá tudo certo para a mãe e o bebê. A meia luz e às vezes uma música de fundo. Sem fórceps e Kristeller. (Dep. 3)
}

As depoentes citam métodos não farmacológicos de alívio da dor no parto como meio de humanizar a assistência. A Rede Cegonha incentiva o uso de tais métodos e apóia práticas de atenção à saúde baseada em evidências científicas, nos termos do documento da Organização Mundial da Saúde, de 1996: "Boas práticas de atenção ao parto e ao nascimento", as práticas citadas pelas participantes do estudo estão entre as citadas no documento.

O Ministério da Saúde (2001) atendendo a recomendações da Organização Mundial de Saúde também traz condutas que são claramente úteis e devem ser encorajadas durante o parto normal como ter um plano individual determinando onde e por quem o parto será realizado, avaliação dos fatores de risco da gravidez durante o cuidado pré-natal, reavaliado a cada contato com o sistema de saúde e no momento do primeiro contato com o prestador de serviços durante o trabalho de parto e parto, monitorização do bem-estar físico e emocional da mulher ao longo do trabalho de parto e parto, oferta de 
líquidos por via oral durante o trabalho de parto e parto, respeito da escolha da mulher quanto ao acompanhante durante o trabalho de parto e parto, entre outros.

Ainda que todos acessórios não estejam disponíveis para a equipe de enfermagem, nota-se conhecimento do que deve ser feito, gerando uma perspectiva positiva em relação às mudanças que estão acontecendo no atendimento ao parto, preconizado pela Rede Cegonha. Desta forma o parto vem a ser um evento mais natural e que dá oportunidade à mulher de participar do processo de nascimento de seu filho. Trazendo ainda autonomia e conhecimento a ser disseminado junto à comunidade em que esta está inserida.

\section{CATEGORIA 3: ENFERMEIRA OBSTÉTRICA COMO REFERÊNCIA NO PARTO}

Questionadas sobre a experiência com o modelo de parto humanizado, as profissionais de enfermagem do centro obstétrico relataram suas vivências à princípio ligadas à assistência do médico, pois até então não existe a figura da enfermeira obstétrica atendendo ao parto. Entendem que alguns médicos buscam fazer o parto humanizado da melhor maneira cabível, que permitem o acompanhante permanecer na sala de pré-parto, embora seja um direito da parturiente e que não necessite de autorização de nenhum profissional responsável pela assistência direta a parturiente.

As falas abaixo refletem a necessidade de discussão coletiva sobre os benefícios da humanização das práticas de atendimento ao parto visto que todos os profissionais envolvidos devem seguir as recomendações do Ministério da Saúde baseadas em evidências científicas e comprovadamente úteis na manutenção da segurança da parturiente e da qualidade da assistência, sendo necessária uma incorporação geral de novas práticas no atendimento ao parto.

\footnotetext{
Alguns médicos procuram fazê-lo da melhor forma. (Dep. 1)

Hoje, no serviço a que pertenço esta realidade está se tornando frequente, a parturiente já pode ficar com acompanhante o tempo todo no pré-parto, porém, o que se deve mudar ainda é o acompanhamento durante o parto que ainda existe resistência médica. (Dep. 7) Alguns médicos procuram fazer esse novo modelo, mas, nem todos aderiram ao modelo completo, mas os que usam são bem vindos, acalma as pacientes da um conforto a mais. (Dep. 9)
}

A maternidade pesquisada tem um histórico de ser espaço de formação médica. Alunos do curso de medicina e residentes de obstetrícia atuam de forma ampla no setor. Essa realidade contribui para o reconhecimento por parte da equipe de saúde desses profissionais como únicos exemplos na assistência à mulher visto que não existe ainda a inserção da enfermeira obstétrica no setor.

Existe um desafio a ser transpassado pelos gestores e profissionais da maternidade pesquisada quando da entrada de novos enfermeiros, pois o enfermeiro obstétrico ainda encontra muitas dificuldades na sua atuação, seja pelos limites impostos pelas estruturas físicas encontradas nas maternidades atualmente, elou rotinas hospitalares, seja pela cultura centrada nos médicos que ainda prevalece (ALMEIDA, GAMA, BAHIANA, 2015) 
Existe confiança na atuação da enfermeira obstétrica por grande parte da equipe pesquisada. A conquista desse espaço pela enfermeira será fundamental para construir a identidade desta profissional e aliar seus conhecimentos com os de outros membros da equipe de saúde com a finalidade de promover um parto mais seguro e humanizado para as mulheres.

As profissionais de enfermagem acreditam que a atuação da enfermeira obstetra somando-se a toda equipe de profissionais trará qualidade e um olhar diferenciado com ênfase aos direitos das parturientes. Entendem ainda, que a enfermeira explicando todo $o$ procedimento do trabalho de parto até o parto, aumentaria o índice de parto normal e diminuiriam as intervenções desnecessárias.

Cada respondente destaca a importância da enfermeira de forma positiva como vemos a seguir:

\begin{abstract}
A enfermeira seria uma referência para que os direitos da gestante e de todos que estejam envolvidos com ela, sejam cumpridos e um profissional a mais prestando assistência à parturiente. (Dep. 5)

Será de grande ajuda, tanto para as técnicas de enfermagem, médicos e principalmente para a gestante, pois teria um atendimento melhor. A enfermeira daria melhor assistência tanto na explicação de como seria o parto normal, quanto o caminho a seguir no trabalho do parto. E o mais importante é que o índice de parto normal aumentaria, pois a enfermeira obstetra tem autonomia para realizar. (Dep. 6)

Acho que daria mais acolhimento para a parturiente, hoje na realidade em que vivo, a enfermeira faria com que os direitos das parturientes fossem respeitados no que diz respeito aos pontos de parto humanizado. (Dep. 3)
\end{abstract}

Percebe-se que o processo de conquista da enfermeira obstetra por espaço e reconhecimento neste setor será árduo, porém gratificante para a equipe e para os estudantes de enfermagem que também atuam no setor durante o estágio supervisionado em saúde da mulher. A enfermeira atendendo aos partos será exemplo para futuros profissionais e para as próprias funcionárias do setor na tentativa de não se limitaras rotinas impostas e agregar conhecimento e uma postura reflexiva para agir da melhor forma frente às situações. Dessa maneira, consolida a profissão e gera assim maior emancipação. (ALMEIDA, GAMA, BAHIANA, 2015)

Entende-se como limitação deste estudo a questão da eleição de apenas uma equipe de enfermagem no interior do estado do Rio de Janeiro, entretanto acredita-se na reprodução deste modelo de reflexão da prática de equipes em outras áreas do país que ainda buscam a inserção da Enfermeira obstétrica em suas salas de parto.

\title{
CONSIDERAÇÕES FINAIS
}

De acordo com a pesquisa realizada com a equipe de enfermagem, que está envolvida no processo de transição para o modelo de parto humanizado, verificou-se que a equipe entende os preceitos da humanização no parto e que mesmo que o centro obstétrico ainda não esteja totalmente preparado de forma física para a humanização das 
práticas, ainda assim a equipe torna disponível uma assistência mais acolhedora e humanizada.

A equipe espera que com a inserção da enfermeira obstétrica atuando na assistência, proporcione experiências de educação em saúde para equipe de enfermagem e também para as parturientes para que estejam conscientes dos seus direitos e possam lutar por eles. E ainda a organização da área física do centro obstétrico, a atitude de acolhimento e que a enfermeira seja uma referência para humanização do atendimento ao parto, estão entre as expectativas da equipe frente a inserção da enfermeira obstétrica na sala de parto.

\section{REFERÊNCIAS}

ALMEIDA, O. S.C.; GAMA, E.R.; BAHIANA, P.M. Humanização do parto: a atuação dos enfermeiros. Revista Enfermagem Contemporânea. v. 4, n. 1, Jan./Jun2015.

CONITEC. Comissão Nacional de Incorporação de Tecnologias no SUS. Diretriz Nacional de Assistência ao Parto Normal. Relatório de recomendação. Brasília: Ministério da Saúde, 2016.

BRASIL, Ministério da Saúde. Portaria no 1.459 de 24 de junho de 2011. Institui, no âmbito do Sistema Único de Saúde - SUS - a Rede Cegonha. Disponível em: http://bvsms.saude.gov.br/bvs/saudelegis/gm/2011/prt1459_24_06_2011.html

BRASIL, Ministério da Saúde. Parto aborto e puerpério: assistência humanizada à mulher. Brasília - DF; 2001. Disponível em:

http://bvsms.saude.gov.br/bvs/publicacoes/cd04_13.pdf. Acesso em 01 de dezembro de 2015.

CAUS, E. C. M. et al. O processo de parir assistido pela enfermeira obstétrica no contexto hospitalar: significados para as parturientes. Esc. Anna Nery, Rio de Janeiro, v. 16, n. 1, p. 34-40, Mar. 2012. Available from <http://www.scielo.br/scielo.php?script=sci_arttext\&pid=S141481452012000100005\&lng=en\&nrm=iso $>$.access on 23 Feb. 2016. http://dx.doi.org/10.1590/S1414-81452012000100005.

COFEN. Conselho Federal de Enfermagem. Lei 7498 de 25 de Junho de 1986. Dispõe sobre o exercício da Enfermagem e dá outras providências. Brasília: COFEN, 1986.

FRELLO, A. T; CARRARO, T. E. Componentes do cuidado de enfermagem no processo de parto. Revista Eletrônica de Enfermagem. v.12, n. 4, p. 660-8, 2010. Disponível em http://www.revistas.ufg.br/index.php/fen/article/view/7056/8487.

GERHALDT, T. E.; SILVEIRA, D.T. Métodos de pesquisa. Universidade Aberta do Brasil - UAB/UFRGS e pelo Curso de Graduação Tecnológica - Planejamento e Gestão para o Desenvolvimento Rural da SEAD/UFRGS. - Porto Alegre: Editora da UFRGS, 2009.

GIL, A. C. Métodos e técnicas de pesquisa social. 6. ed. - São Paulo : Atlas, 2008. 
MOURA, M.A.V. A institucionalização do parto e a humanização da assistência. Revista de Enfermagem Escola Anna Nery, v.8, n.2, agosto 2004.

PEREIRA, S. S. et al. Parto natural: a atuação do enfermeiro diante da assistência humanizada. Tempus, actas de saúde colet, v.10, n. 3, p. 199-213, 2016. 